\title{
Lead Site Ventral
}

National Cancer Institute

\section{Source}

National Cancer Institute. Lead Site Ventral. NCI Thesaurus. Code C135392.

A bipolar electrocardiog ram limb lead which records the voltage with the positive electrode on the hindquarters proximal to the sacrum and the negative electrode near the apex of the heart (located in the ICS of left 5-6 rib close to the sternum). (CDISC) 